\title{
Increased flexibility in the delivery of ultrapure water
}

\section{The Milli- $Q^{\circ}$ Advantage system offers flexibility in the quality and delivery of various ultrapure water grades in laboratories. A single purification unit can be connected to up to three point-of-use dispensers, which can be equipped with different purifiers to provide the necessary water quality for various applications. The water can be delivered at up to $2 \mathrm{l} / \mathrm{min}$ where it is required, minimizing the need for storage. The validation capabilities of the system allow operation in quality-controlled environments and compliance with various laboratory standards.}

Modern laboratories often combine several areas of expertise. Analytical labs work with proteins and DNA, whereas molecular biology labs increasingly use high-performance liquid chromatography (LC) and mass spectrometry (MS) techniques. In the pharmaceutical industry, protein-based assays are performed for drug discovery together with LC-MS as well as cell-based assays for lead selection and qualification steps. Environmental laboratories gather standard data on ion dosage, trace-level analysis of persistent organic pollutants and microbiology. As these laboratory environments change, a broader range of techniques is used to address wider and more specific needs.

The processes of performing LC-MS, analyzing ions, growing mammal cells or amplifying DNA have different sensitivities to water contaminants; and several types of water qualities are often required within one laboratory. Additionally, laboratories may encounter strict quality processes and compliance standards, including calibration documentation of monitoring devices and qualification of water purification units.

Millipore has developed a new water purification system that responds to all these needs. This system includes a main water purification unit and point-of-use dispensers. The main purification unit, which can be located conveniently under a lab bench, provides ultrapure water with low total organic carbon (TOC) levels (less than 5 parts per billion) and high resistivity $\left(18.2 \mathrm{M} \Omega \times \mathrm{cm}\right.$ at $\left.25^{\circ} \mathrm{C}\right)$. It can be connected to up to three point-of-use dispensers equipped with applicationspecific purifiers, which deliver purified water at an adaptable flow rate and allow the automatic delivery of a selected water volume.

\section{Main purification unit}

The main purification unit combines ion exchange resins, activated carbon and ultraviolet photo-oxidation water purification techniques. Mixed-bed, high-quality ion-exchange resins remove ions to trace levels (ng/l or parts per trillion). Using a dual-wavelength low-pressure

Stéphane Mabic, Daniel Darbouret \& Jean-François Pilette

Millipore Corporation, Bioscience Division, 17 Cherry Hill Dr., Danvers, Massachusetts 01923, USA.Correspondence should be addressed to S.M. (stephane_mabic@millipore.com).

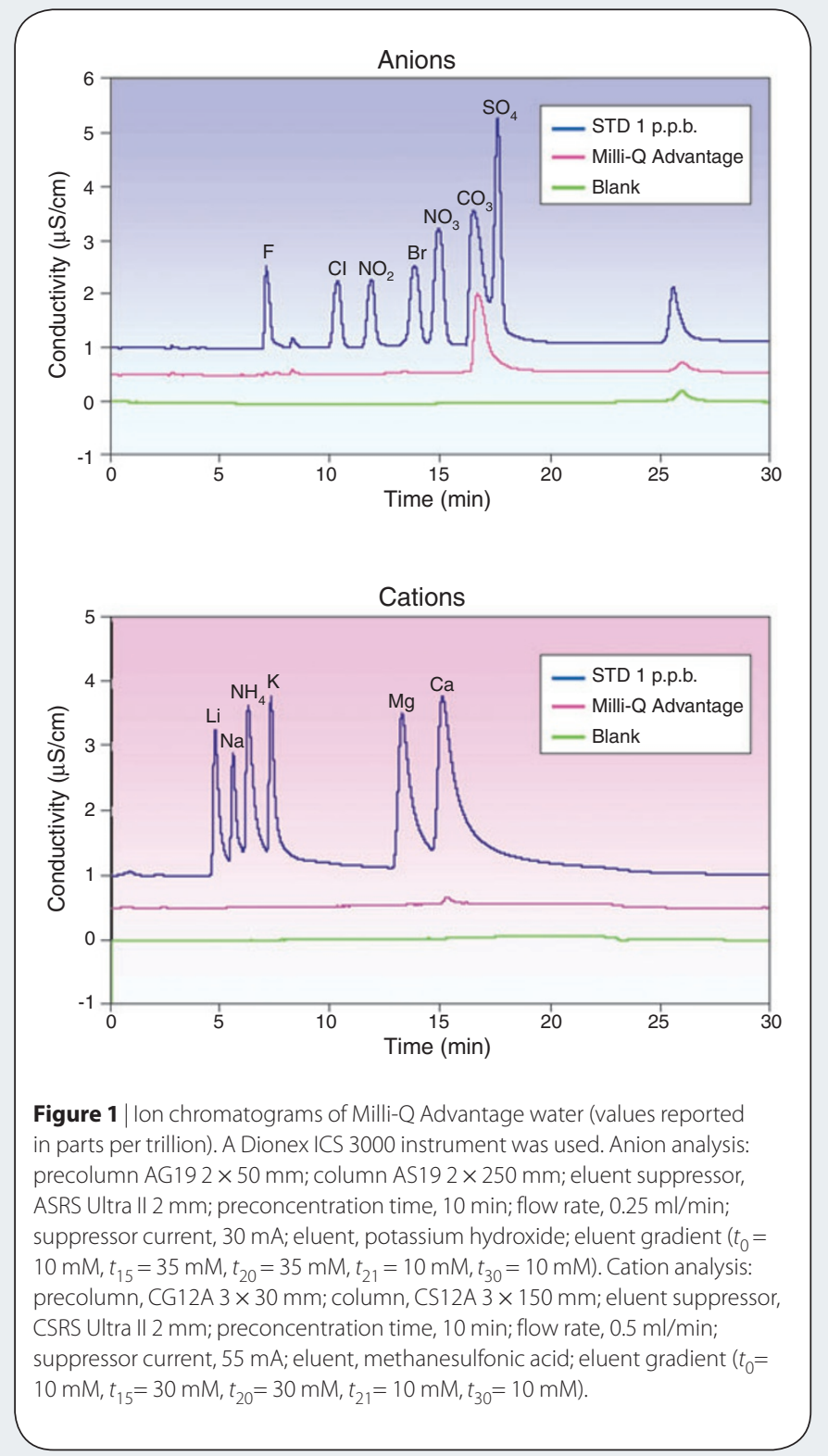




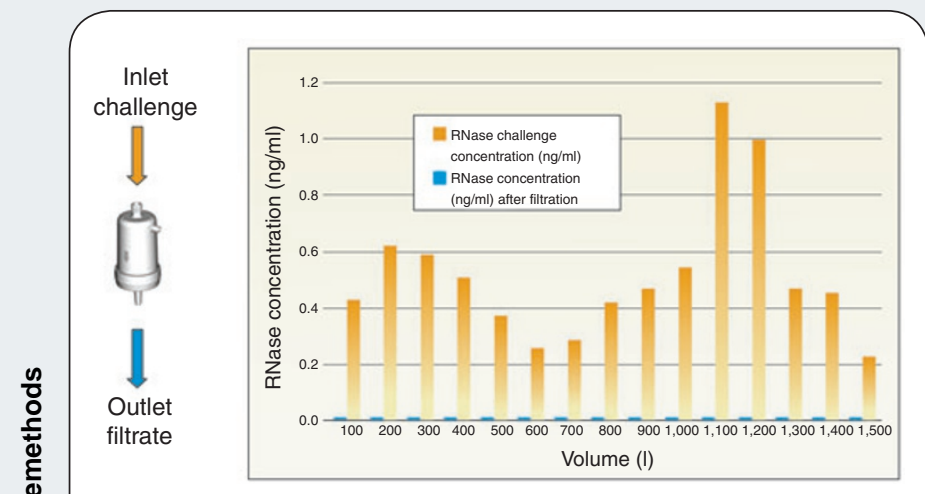

Figure $\mathbf{2} \mid$ Removal of RNases using ultrafiltration. Water was spiked with RNase in a reservoir and then filtered through the BioPak cartridge. Nuclease concentration was measured in the challenge solution and filtrate using a fluorescence detection kit (RNase alert kit, Ambion).

mercury lamp, ultraviolet photo-oxidation step induces the breakdown of organic molecules and results in a decreased TOC level. Organics also are adsorbed on the synthetic activated carbon used in the Q-Gard ${ }^{\circledR}$ and Quantum ${ }^{\text {TM }}$ EX cartridges. When reverse-osmosis water was used to feed the purification unit, more than 4,000 I of ultrapure water were produced from a single set of cartridges.

\section{Point-of-use purifiers}

The water produced by the main unit is distributed to three point-of-use dispensers, each equipped with a different purifier. A $0.22 \mu \mathrm{m}$ MilliPak ${ }^{\circledR}$ membrane filter provides particulate-free and bacteria-free water suitable for liquid chromatography applications (high-performance liquid chromatography, ultrahigh-performance liquid chromatography, nano LC, ion chromatography) and MS. An ion chromatography example (Fig. 1) shows that ionic concentration is reduced to trace levels.

$\mathrm{A} \mathrm{BioPak}^{\mathrm{TM}}$ polysulfone ultrafiltration cartridge delivers nuclease-free, endotoxin-free water with a bacterial count below one colony-forming unit per ml, certified for a three-month period. The ultrafiltered water is suitable for molecular biology experiments, and when fresh water is used, there is no need to treat the water with diethyl pyrocarbonate for work with RNA. This water can also be used to prepare serum-free media for mammalian cell cultures. An example of the ultrafilter performance is highlighted by the removal of RNase, where RNase levels in ultrafiltered water were consistently below the detection limit (Fig. 2).

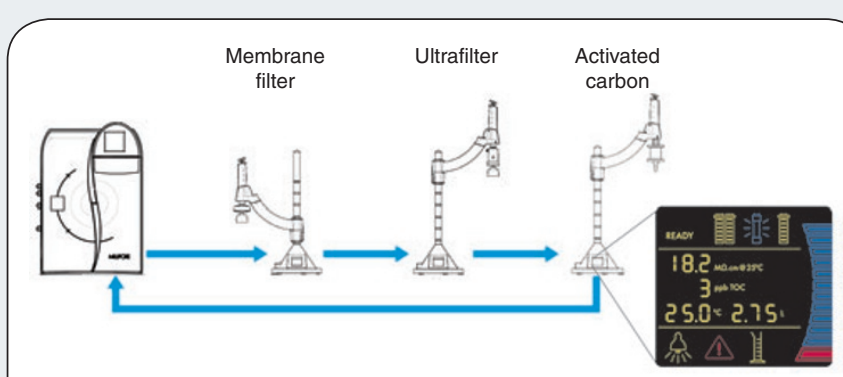

Figure $\mathbf{3}$ | Configurations for the Milli-Q Advantage system.
An activated carbon purifier was selected to remove traces of small organic molecules present in water. The efficiency of the purifier for removing small organics from water was tested at various spike-in concentrations of these organics. The molecules selected are persistent organic pollutants that are subject to regulations in various geographies. Analyses were performed using gas chromotography and MS. Bisphenol A (BPA), di-n-butylphthalate (DBP), diethyl-phenylphthalate and nonylphenol were spiked into the water at $0.2,0.5$ or $2 \mu \mathrm{g} / \mathrm{l}$ in three successive experiments. Concentrations detected after purification via the activated carbon were as follows:

1. $0.2 \mu \mathrm{g} / \mathrm{l}$ spike-in - BPA, $0.016 \mu \mathrm{g} / \mathrm{l}$; DBP, $0.05 \mu \mathrm{g} / \mathrm{l}$; diethylphenylphthalate, $0.03 \mu \mathrm{g} / \mathrm{l}$; nonylphenol $0.02 \mu \mathrm{g} / \mathrm{l}$

2. $0.5 \mu \mathrm{g} / \mathrm{l}$ spike-in - BPA, $0.003 \mu \mathrm{g} / \mathrm{l}$; DBP, $0.08 \mu \mathrm{g} / \mathrm{l}$; diethylphenylphthalate, $0.04 \mu \mathrm{g} / \mathrm{l}$; nonylphenol $0.02 \mu \mathrm{g} / \mathrm{l}$

$3.2 \mu \mathrm{g} / \mathrm{l}$ spike-in - BPA, $0.013 \mu \mathrm{g} / \mathrm{l}$; DBP, $0.05 \mu \mathrm{g} / \mathrm{l}$; diethylphenylphthalate, $0.04 \mu \mathrm{g} / \mathrm{l}$; nonylphenol, $0.01 \mu \mathrm{g} / \mathrm{l}$.

\section{Design and use}

An important concept in the design of this new water purification system is the ability to wall-mount or place the main cabinet under the bench, leaving only the Q-POD ${ }^{\mathrm{TM}}$ point-of-use dispenser on the bench. All the necessary daily information regarding water purity, volume dispenses, alerts and alarms are accessible on the Q-POD dispenser, which becomes the primary user interface. There is no need to access the main unit on a daily basis.

Additionally, the Q-POD dispenser increases the flexibility of water delivery, as it can be set up exactly where needed. The Q-POD dispensers can be installed three meters apart (Fig. 3) from each other and dispense water from the main unit in different lab locations.

Water quality is verified at the outlet of the main unit by a resistivity meter for ionic detection and a TOC meter for organic detection at the parts-per-billion level. Both monitoring devices are calibrated and designed for compliance with the suitability tests defined by the United States Pharmacopeia ( $\$ 643$ and $§ 645$ ) and other standards. The patented in-line coaxial resistivity cell is referenced to a primary cell developed by a metrology institute. Full-qualification support is available for the overall system, which can be validated to meet the quality requirements of pharmaceutical, clinical or microelectronic environments.

\section{Conclusion}

The management of diverse and specific needs within the laboratory has been a driving force in developing this unique water purification system. This combination of technologies provides high-quality water with low TOC and high resistivity. Finally, this breadth of point-ofuse purifiers addresses emerging needs as well as those for existing applications.

\section{ACKNOWLEDGMENTS}

We acknowledge I. Kano, J. Bôle, C. Regnault and E. Castillo for their research and contribution to this manuscript.

This article was submitted to Nature Methods by a commercial organization and has not been peer reviewed. Nature Methods takes no responsibility for the accuracy or otherwise of the information provided. 